Article

\title{
Comparative Analysis of the Smear Layer Removal Capability between EndoVac and Endoactivator Endodontic Irrigation Systems at the Root Canal System and Isthmus: A Micro-Computed Tomography Analysis
}

\author{
Vicente Faus-Llácer ${ }^{1}$, Mauricio Luna-Roa ${ }^{1}$, Ignacio Faus-Matoses ${ }^{1}$, Celia Ruiz-Sánchez ${ }^{1}$, \\ Álvaro Zubizarreta-Macho ${ }^{2, *}$, Salvatore Sauro ${ }^{3,4}$ and Vicente Faus-Matoses ${ }^{1}$ \\ 1 Department of Stomatology, Faculty of Medicine and Dentistry, University of Valencia, 46010 Valencia, Spain; \\ fausvj@uv.es (V.F.-L.); anmaulu@alumni.uv.es (M.L.-R.); ignacio.faus@uv.es (I.F.-M.); \\ ceruizsan@gmail.com (C.R.-S.); vicente.faus@uv.es (V.F.-M.) \\ 2 Department of Endodontics, Faculty of Health Sciences, Alfonso X El Sabio University, 28691 Madrid, Spain \\ 3 Department of Dentistry, Faculty of Health Sciences, CEU Cardenal Herrera University, 46115 Valencia, \\ Spain; salvatore.sauro@uchceu.es \\ 4 Department of Therapeutic Dentistry, I.M. Sechenov First Moscow State Medical University, \\ 119146 Moscow, Russia \\ * Correspondence: amacho@uax.es
}

Received: 22 September 2020; Accepted: 5 October 2020; Published: 10 October 2020

\begin{abstract}
The aim of this comparative study is to analyze the efficacy of EndoVac and Endoactivator endodontic irrigation systems for removing the endodontic smear layer present in the coronal, middle, and apical root third of the root canal system (RCS) and the isthmus from mesial roots from the first lower molar teeth using micro-computed tomography (micro-CT) analysis. The study was performed on 40 mesial roots that were randomly assigned to the following groups: Group A, EndoVac endodontic irrigation system (EV) $(n=10)$; Group B, Endoactivator endodontic irrigation system (EA) $(n=10)$; Group C, Root canal systems performed with F2 ProTaper Gold endodontic rotary system but not irrigated (Positive control) $(n=10)$; Group D, Root canal systems not performed or irrigated (Negative control) $(n=10)$. The samples were exposed to micro-CT analysis and the mesial roots were segmented using an advanced image segmentation technique based on partial differential equations (ROI: $10 \times 10 \times 10 \mathrm{~mm}$ ) and the root canal systems and isthmus were reconstructed at a resolution of 25 microns per voxel. The EA study group showed statistically significant different residual endodontic smear layer volume $\left(0.48 \pm 0.24 \mathrm{~mm}^{3}\right)$ compared to the EV study group $\left(0.18 \pm 0.15 \mathrm{~mm}^{3}\right)$ $(p=0.016)$. The EV endodontic irrigation system performed a higher smear layer removal at coronal and middle root thirds, compared to the EA endodontic irrigation system; however, the EA endodontic irrigation system performed a higher smear layer removal at the apical root third, compared to the EV endodontic irrigation system.
\end{abstract}

Keywords: micro-computed tomography; non-surgical endodontic retreatment; smear layer removal; isthmus; EndoVac; Endoactivator

\section{Introduction}

The most widely used endodontic irrigating solution is sodium hypochlorite $(\mathrm{NaOCl})$, which acts as a bactericide agent and dissolves the organic tissue present in the root canal system (RCS); however, it is not effective in endodontic smear layer removal. Chelating irrigants, such as ethylenediaminetetraacetic 
acid (EDTA), have shown their effectiveness in endodontic smear layer removal and improving RCS disinfection [1,2]. During root canal surgery, the application of endodontic instruments onto the dentinal root canal walls produces hard tissue debris deposition within the RCS, which may contain bacterial cells [1]. It can also interfere with the endodontic irrigation agents and root canal filling materials of the RCS, preventing RCS disinfection and sealing, especially in anatomically complex areas, such as the isthmus areas in mesial roots of lower molar teeth [2,3]. Isthmus areas are considered an important anatomical feature because they can contain smear layer remains of dental pulp tissue, necrotic tissues, and microorganisms, which can promote root canal re-infection after treatment [4]. Tahmasbi et al. reported a prevalence of isthmus areas in the mesial root from the first lower molar teeth of $65.7 \%$ [5], whereas Kim et al. reported a frequency range from $20 \%$ to $70 \%$ [6]. The isthmus, according to its anatomical characteristics, is classified into five categories: Type I-There are two separate root canals, but union does not appear. Type II-An isthmus between the two separate root canals is observed. Type III-There are three root canals connected by an isthmus. Type IV-There are two elongated root canals connected in the center. Type V-There is a single, very wide and elongated root canal $[4,7]$.

Traditionally, disinfection of the RCS has been performed by means of a passive irrigation procedure through endodontic irrigation syringes. However, this disinfection approach has demonstrated limited efficacy to clean the apical third of the RCS and the anatomical irregularities of the RCS, such as the isthmus. Therefore, new approaches have been developed to improve the cleaning capability of traditional disinfection procedures. The Endoactivator (Dentsply Maillefer, Ballaigues, Switzerland) endodontic irrigation system can promote the penetration of the irrigant agent within the dentinal tubules of the RCS by means of continuous sonic movement [8]. The EndoVac (Dentsply Maillefer, Ballaigues, Switzerland) endodontic irrigation system can also safely reduce the bacterial load present in the RCS, ensuring the presence of the irrigant agent in the apical third of the RCS and also preventing vapor lock formation, which avoids disinfection of the irrigant agent in the apical portion of the RCS $[9,10]$. The device allows for constantly renewed $\mathrm{NaOCl}$ irrigation throughout the root canal system by means of a negative apical pressure system. Two cannulas allow this flow of $\mathrm{NaOCl}$ : a macro cannula that introduces the $\mathrm{NaOCl}$ irrigation agent at the access cavity, and a micro cannula located in the apical constriction that aspirates the $\mathrm{NaOCl}$ irrigation agent and evacuates it from the RCS.

The aim of the present study is to compare the efficacy of the EndoVac and Endoactivator endodontic irrigation systems for removing the endodontic smear layer present in the coronal, middle, and apical root third of the RCS and the isthmus from mesial roots from first lower molar teeth using micro-CT analysis, with a null hypothesis $\left(\mathrm{H}_{0}\right)$. This hypothesis determines that there would exist no difference between the EndoVac and Endoactivator endodontic irrigation systems for removing the endodontic smear layer present in the coronal, middle, and apical root third of the RCS and the isthmus from mesial roots from first lower molar teeth using micro-CT analysis.

\section{Experimental Section}

\subsection{Study Design}

A total of 40 first lower molar teeth with two canals and isthmus in the mesial root and extracted for periodontal reasons, with mature roots, absence of previous root canal treatment, calcium metamorphosis, and root resorptions were selected. This study was performed at the Department of Stomatology of the University of Valencia (Valencia, Spain), between February and July 2019. A randomized controlled experimental trial was performed attending to the German Ethics Committee's statement for the use of organic tissues in medical research, which was approved by the University of Valencia Ethics Committee (process no. 12151). All of the patients were informed and consented to transfer their teeth for the study. 


\subsection{Experimental Procedure}

The crowns of the teeth were removed between $1 \mathrm{~mm}$ and $3 \mathrm{~mm}$ under the cement-enamel junction to standardize dental samples to $10 \mathrm{~mm}$ in length. The teeth were submitted to digital radiography in both buccolingual and mesiodistal directions to assess the RCS anatomy. The working length $(\mathrm{WL})$ of the RCS was determined using an operative microscope at $12 \times$ magnification (Zeiss Dental Microscope, Oberkochen, Germany) until the emergence of a size $8 \mathrm{~K}$-file (Dentsply Maillefer, Ballaigues, Switzerland) was visible at the apical foramen of the RCS. Then, the samples were randomly placed (Epidat 4.1, Galicia, Spain) into the following study groups: Group A, EndoVac endodontic irrigation system (Dentsply Maillefer, Baillagues, Switzerland) (EV) $(n=10)$; Group B, Endoactivator endodontic irrigation system (Dentsply Maillefer, Ballaigues, Switzerland) (EA) $(n=10)$; Group C, RCS performed with F2 ProTaper Gold endodontic rotary system (Dentsply Maillefer, Baillagues, Switzerland) but not irrigated (Positive control) $(n=10)$; Group D, RCS not performed or irrigated (Negative control) $(n=$ 10).

The RCSs were randomly assigned to the above-mentioned study and control groups. Surgery for the EV and EA study groups and Positive control group was performed by using the ProTaper Gold endodontic rotary system up to an F2 endodontic rotary file (Dentsply Maillefer, Ballaigues, Switzerland), using a 6:1 reduction handpiece (X-Smart plus, Dentsply Maillefer, Ballaigues, Switzerland) at $300 \mathrm{rpm}$ and $2 \mathrm{~N} / \mathrm{cm}$ torque, according to the manufacturer's recommendations. The RCSs randomly assigned to the EV study group were irrigated with $5 \mathrm{~mL}$ of $5.25 \% \mathrm{NaOCl}$ (Clorox, Oakland, CA, USA) with a 0.3-mm-diameter endodontic needle (Miraject Endo Luer, Hager and Werken, Duisburg, Germany) inserted $1 \mathrm{~mm}$ into the WL. Furthermore, the disinfection of the RCS was improved by using the Endoactivator endodontic irrigation system (Dentsply Maillefer, Ballaigues, Switzerland) between each endodontic file of the sequence. The final irrigation procedure was performed with $5 \mathrm{~mL}$ of $17 \%$ ethylenediaminetetraacetic acid (EDTA) (SmearClear, SybronEndo, CA, USA), $5 \mathrm{~mL}$ of $5.25 \% \mathrm{NaOCl}$, and $5 \mathrm{~mL}$ of sterile saline solution (Braun ${ }^{\circledR}$, Melsungen, Germany). However, the RCSs randomly assigned to the EA study group were irrigated with $5 \mathrm{~mL}$ of $5.25 \% \mathrm{NaOCl}$ (Clorox, Oakland, CA, USA) with a 0.3-mm-diameter endodontic needle (Miraject Endo Luer, Hager and Werken, Duisburg, Germany) inserted $1 \mathrm{~mm}$ into the WL. Furthermore, the disinfection of the RCS was improved by using the EndoVac endodontic irrigation system (Dentsply Maillefer, Ballaigues, Switzerland) between each endodontic file of the sequence. The final irrigation procedure was performed with $5 \mathrm{~mL}$ of $17 \%$ EDTA (SmearClear, SybronEndo, CA, USA), left in the canal for 1 min with $5 \mathrm{~mL}$ of $5.25 \%$ activated $\mathrm{NaOCl}$, and $5 \mathrm{~mL}$ of sterile saline solution (Braun ${ }^{\circledR}$, Melsungen, Germany). Then, the RCSs randomly assigned to the EV and EA study groups were dried with sterile paper points (Dentsply Maillefer, Ballaigues, Switzerland) and the teeth were then stored in an incubator (mco-18aic, Sanyo, Moriguchi, Osaka, Japan) $\left(37^{\circ} \mathrm{C}, 100 \%\right.$ relative humidity). The RCSs randomly assigned to the Negative control group were neither shaped nor cleaned with irrigation solutions. All of the root canal treatments were performed by a single clinician.

\subsection{Micro-CT Scanning}

A micro-CT scan (Micro-CAT II, Siemens Preclinical Solutions, Knoxville, TN, USA) was performed to the RCS to analyze the residual smear layer volume present in the coronal, middle, and apical third of the RCS and the isthmus, the RCS volume, and the relationship between them at coronal, middle, and apical third of the RCS and at the interradicular isthmus with the following exposure parameters: $90 \mathrm{kV}, 88 \mu \mathrm{A}$, isotropic resolution of $50 \mu \mathrm{m}$, and $360^{\circ}$ rotation. The tomographic three-dimensional images containing the entire tooth had a total of 512 slices, with isotropic 50 microns voxel size and a resolution of $512 \times 512$ pixels per slice. The isthmus presence was analyzed on the micro-CT scan (Micro-CAT II, Siemens Preclinical Solutions, Knoxville, TN, USA) at coronal, middle, and apical third of the root canal system (Figure 1). 
A
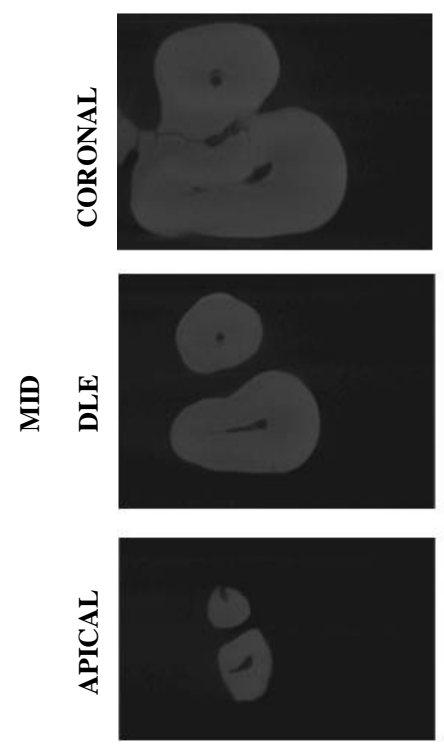

B
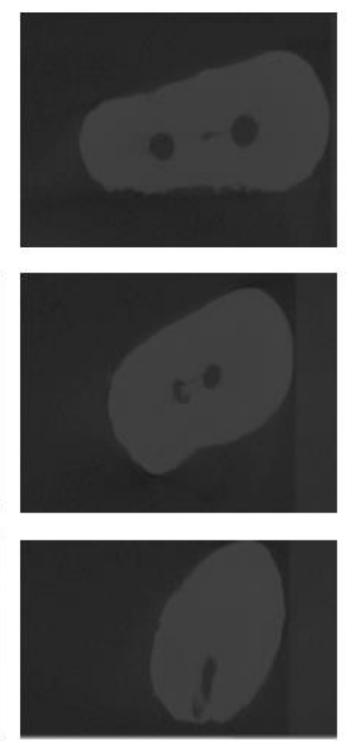

C
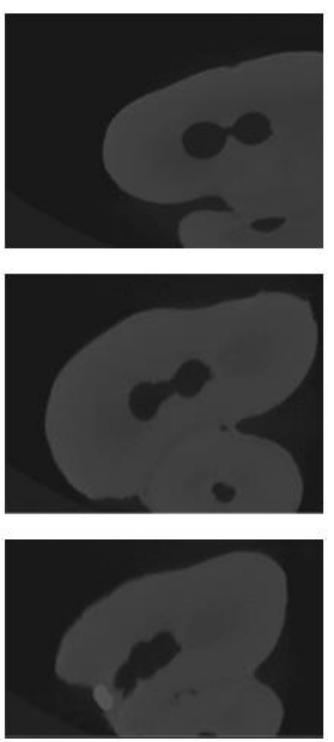

D
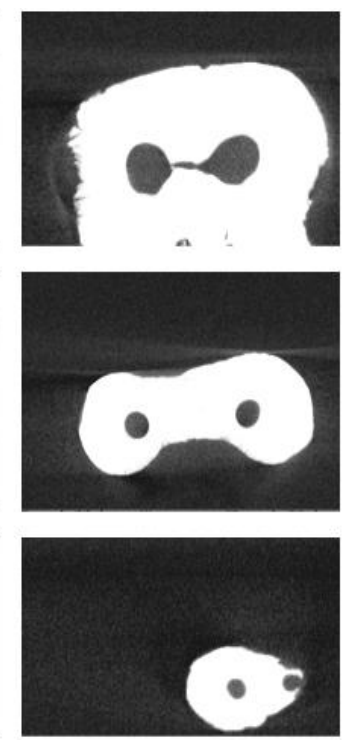

Figure 1. Analysis of the isthmus presence on the transversal cross sections of the coronal, middle, and apical third of the RCS of (A) Negative control group, (B) Positive control group, (C) EndoVac endodontic irrigation system (EV) study group, and (D) Endoactivator endodontic irrigation system (EA) study group.

\subsection{Measurement Procedure}

The analysis of the endodontic smear layer present in the coronal, middle, and apical third of the RCS and the isthmus was performed through image processing software (ImageJ, National Institutes of Health, Bethesda, MD, USA) after defining and segmenting the mesial root (ROI: $10 \times 10 \times 10 \mathrm{~mm}$ ) of the dental samples. Next, the segmented mesial roots were reconstructed at a resolution of 25 microns per voxel (Quantum 3.0, San Jose, CA, USA). Then, the RCSs forming on the segmented mesial roots were divided using an advanced image segmentation technique based on partial differential equations (Level Sets, National Institutes of Health, Bethesda, MD, USA) which allow progressive differentiation between neighboring pixels and define the anatomy of the RCS (Figure 1). The algorithm is manually initialized in the first slice of the axial view of the volume, where the user draws a contour outside, but close to, the channel. The segmentation technique method then deforms the contour towards the inside, until convergence is reached (i.e., the channel is segmented for the first slice). Then, the calculated contour is expanded by a fixed number of pixels (i.e., 6 pixels) as initialization for the next slice, where segmentation technique is applied again. This process is iteratively applied for every axial slice of the volume, until the whole channel is segmented in 3D. Once the channel has been retrieved, the tooth debris inside the channel is segmented by thresholding the volume of interest (i.e., interior of the channel). Small particles are eliminated from the debris' segmentation mask as a final denoising step. The resulting segmentation mask may be manually edited, by adding or deleting objects, in order to correct for possible inaccuracies in the automatic segmentation. Finally, tooth debris volume, total channel volume, and the ratio between both are calculated for apical, medial and coronal sections of the tooth.

Then, the residual endodontic smear layers present in the coronal, middle, and apical third of the RCS and the isthmus were segmented by thresholding the volume of interest (Figure 2A-D). 
A

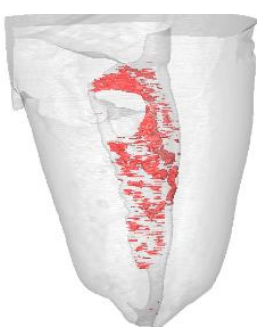

B

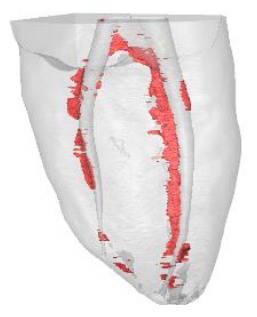

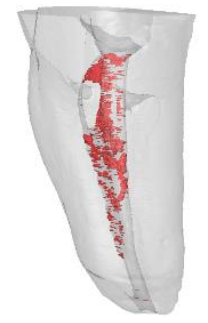

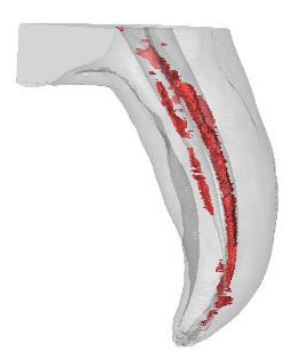

C

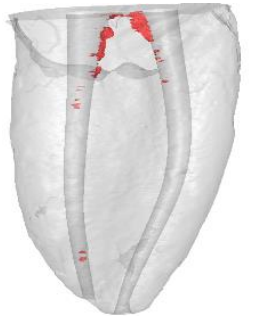

D

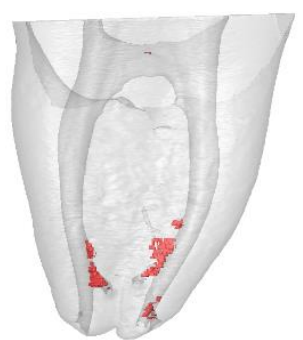

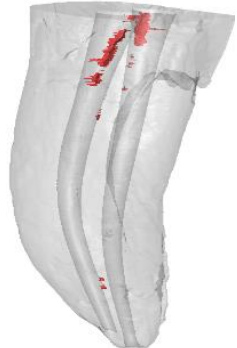

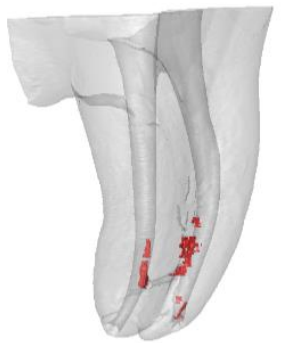

Figure 2. Reconstructed three-dimensional micro-CT images of (A) Negative control group, (B) Positive control group, (C) EV study group, and (D) EA study group. Residual smear layer volume present in the coronal, middle, and apical third of the root canal system (RCS) and the isthmus (red).

Finally, the residual smear layer volume present in the coronal, middle, and apical third of the root canal system and at the interradicular isthmus, the root canal system volume, and the relationship between them at the coronal, middle, and apical third of the root canal system and the isthmus were analyzed and compared by a blinded examiner (Amira 5.2 software, Thermo Fisher Scientific, Bilbao, Spain).

\subsection{Statistical Tests}

The variables of interest were registered for statistical analysis (SPSS 22.00, Microsoft Inc, Redmond, WA, USA). The mean, median, and standard deviation (SD) were used to perform the descriptive statistical analysis for the quantitative variables. A comparative analysis was performed by comparing the median residual endodontic smear layer volume present in the coronal, middle, and apical third of the RCS and the isthmus $\left(\mathrm{mm}^{3}\right)$, the root canal system volume $\left(\mathrm{mm}^{3}\right)$, and the relationship between them at coronal, middle, and apical third of the RCS and the isthmus (\%) between the EndoVac and Endoactivator endodontic irrigation systems and Positive and Negative control groups using ANOVA and Kruskal-Wallis tests- $p<0.05-$ was considered statistically significant.

\section{Results}

The mean, median, and SD values of the residual endodontic smear layer volume present in the coronal, middle, and apical third of the RCS and the isthmus $\left(\mathrm{mm}^{3}\right)$ are presented in Table 1 and Figure $3 \mathrm{~A}-\mathrm{C}$. 
Table 1. Descriptive analysis of the residual endodontic smear layer present in the coronal, middle, and apical third of the RCS and the isthmus $\left(\mathrm{mm}^{3}\right)$ of the study groups.

\begin{tabular}{cccccc}
\hline & & EV & EA & Positive Control & Negative Control \\
\hline \multirow{6}{*}{ Coronal third } & $n$ & 10 & 10 & 10 & 10 \\
& Mean & 0.18 & 0.48 & 0.42 & 0.21 \\
& Median & 0.15 & 0.52 & 0.42 & 0.15 \\
& SD & 0.15 & 0.24 & 0.26 & 0.15 \\
& Maximum & 0.00 & 0.12 & 0.03 & 0.01 \\
Middle third & 0.40 & 0.79 & 0.84 & 0.48 \\
\hline & $n$ & 10 & 10 & 10 & 10 \\
& Mean & 0.24 & 0.41 & 0.37 & 0.18 \\
& Median & 0.22 & 0.42 & 0.35 & 0.13 \\
& SD & 0.26 & 0.32 & 0.29 & 0.04 \\
& Minimum & 0.01 & 0.00 & 0.01 & 0.58 \\
& Maximum & 0.90 & 0.89 & 0.84 & 10 \\
Apical third & Median & 0.10 & 0.08 & 10 & 0.05 \\
& SD & 0.18 & 0.06 & 0.12 & 0.04 \\
& Mean & 0.17 & 10 & 0.08 & 0.05 \\
& Minimum & 0.01 & 0.01 & 0.01 & 0.00 \\
& Maximum & 0.51 & 0.18 & 0.25 & \\
\hline
\end{tabular}

A

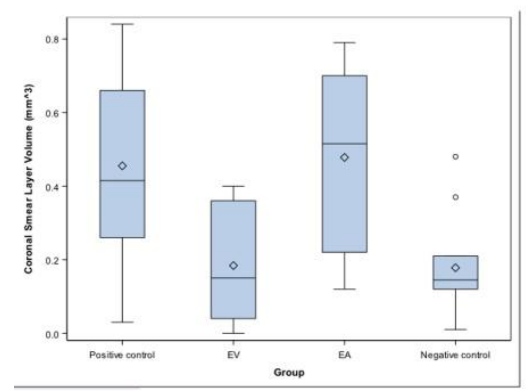

B

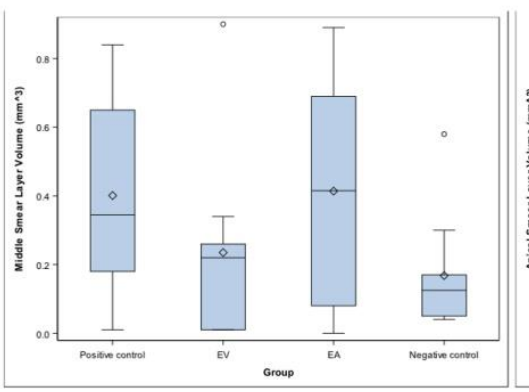

C

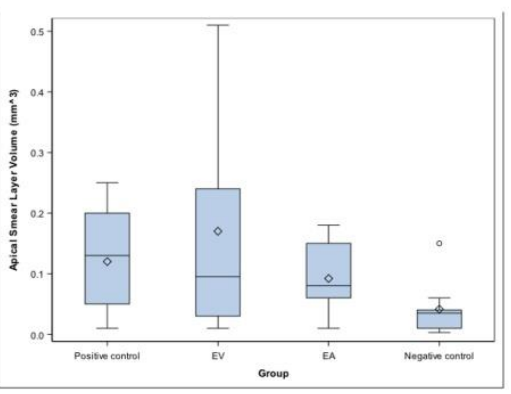

Figure 3. Box plot of the residual endodontic smear layer present in the coronal (A), middle (B), and apical third $(C)$ of the RCS and the isthmus $\left(\mathrm{mm}^{3}\right)$ of the study groups.

The ANOVA test revealed statistically significant differences between the residual endodontic smear layer volume of the RCSs randomly assigned to the Positive control group at the coronal root third $\left(0.42 \pm 0.26 \mathrm{~mm}^{3}\right)$, compared to the EV study group $\left(0.18 \pm 0.15 \mathrm{~mm}^{3}\right)(p=0.030)$ and Negative control group $\left(0.21 \pm 0.15 \mathrm{~mm}^{3}\right)(p=0.026)$. Furthermore, the Kruskal-Wallis test showed statistically significant differences between the residual endodontic smear layer volume of the RCSs randomly assigned to the EA study group $\left(0.48 \pm 0.24 \mathrm{~mm}^{3}\right)$, compared to EV study group $\left(0.18 \pm 0.15 \mathrm{~mm}^{3}\right)$ $(p=0.016)$ and Negative control group $\left(0.21 \pm 0.15 \mathrm{~mm}^{3}\right)(p=0.014)$ (Table 1, Figure 3A). However, the Kruskal-Wallis test did not show statistically significant differences between the study groups regarding the residual endodontic smear layer volume at the middle root third $(p=0.172)$ (Table 1, Figure 3B) or the apical root third $(p=0.079)$ (Table 1, Figure 3C).

The mean, median, and SD values of the root canal system volume in the coronal, middle, and apical third of the RCS and the isthmus $\left(\mathrm{mm}^{3}\right)$ are presented in Table 2 and Figure $4 \mathrm{~A}-\mathrm{C}$. 
Table 2. Descriptive analysis of the residual endodontic smear layer present in the coronal, middle, and apical third of the RCS and the isthmus $\left(\mathrm{mm}^{3}\right)$ of the study groups.

\begin{tabular}{cccccc}
\hline & & EV & EA & Positive Control & Negative Control \\
\hline \multirow{5}{*}{ Coronal third } & $n$ & 10 & 10 & 10 & 10 \\
& Mean & 5.74 & 6.25 & 5.90 & 1.73 \\
& Median & 5.04 & 6.42 & 5.28 & 1.82 \\
& Minimum & 2.24 & 1.60 & 2.62 & 1.17 \\
& Maximum & 9.03 & 3.87 & 3.25 & 0.37 \\
Middle third & $n$ & 8.55 & 9.02 & 9.04 \\
& Mean & 3.23 & 4.10 & 10 & 10 \\
& Median & 3.08 & 3.98 & 3.01 & 1.06 \\
& SD & 1.26 & 1.57 & 2.95 & 0.96 \\
& Minimum & 1.17 & 1.99 & 1.31 & 0.76 \\
& Maximum & 5.15 & 6.91 & 1.58 & 2.87 \\
\hline \multirow{6}{*}{ Apical third } & 10 & 4.76 & 10 \\
& $n$ & 10 & 10 & 10 & 0.60 \\
& Mean & 2.1 & 1.94 & 1.78 & 0.04 \\
& Median & 0.10 & 0.08 & 0.13 & 0.49 \\
& SD & 0.88 & 0.92 & 1.26 & 0.14 \\
& Minimum & 0.78 & 1.07 & 0.50 & 4.02 \\
\hline
\end{tabular}

A

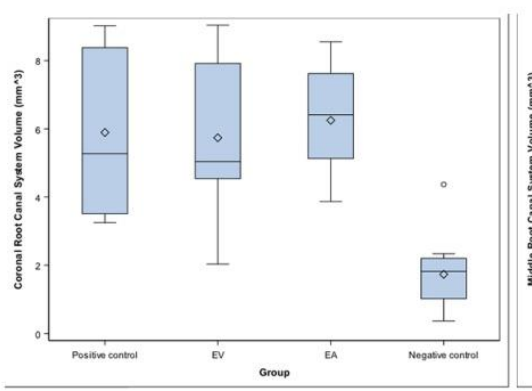

B

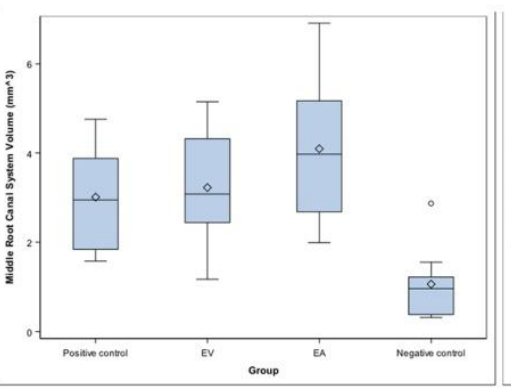

C

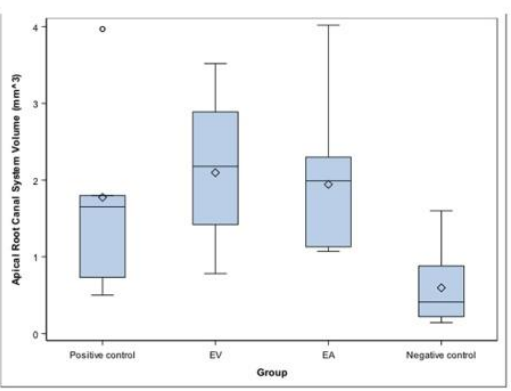

Figure 4. Box plot of the root canal system volume in the coronal (A), middle (B), and apical third (C) of the RCS and the isthmus $\left(\mathrm{mm}^{3}\right)$ of the study groups.

The Kruskal-Wallis test revealed statistically significant differences between the RCS volume of the root canals systems randomly assigned to the Negative control group at the coronal root third $\left(1.82 \pm 1.17 \mathrm{~mm}^{3}\right)$, compared to the EV study group $\left(5.04 \pm 2.24 \mathrm{~mm}^{3}\right)(p=0.016)$, EA study group $\left(6.42 \pm 1.60 \mathrm{~mm}^{3}\right)(p=0.011)$, and Positive control group $\left(5.28 \pm 2.62 \mathrm{~mm}^{3}\right)(p=0.019)$ (Table 2, Figure 4A). The Kruskal-Wallis test revealed also statistically significant differences between the RCS volume of the RCSs randomly assigned to the Negative control group at the middle root third $\left(0.96 \pm 0.76 \mathrm{~mm}^{3}\right)$, compared to the EV study group $\left(3.08 \pm 1.26 \mathrm{~mm}^{3}\right)(p=0.023)$, EA study group $\left(3.98 \pm 1.57 \mathrm{~mm}^{3}\right)(p=0.014)$, and Positive control group $\left(2.95 \pm 1.31 \mathrm{~mm}^{3}\right)(p=0.019)$ (Table 2, Figure 4B). In addition, the Kruskal-Wallis test revealed statistically significant differences between the RCS volume of the RCSs randomly assigned to the Negative control group at the apical root third $\left(0.04 \pm 0.49 \mathrm{~mm}^{3}\right)$, compared to the EV study group $\left(0.10 \pm 0.88 \mathrm{~mm}^{3}\right)(p=0.023)$ and EA study group $\left(0.08 \pm 0.92 \mathrm{~mm}^{3}\right)(p=0.032)$. However, there were no statistically significant differences between the RCS volume of the EV and EA study groups ( $p=1.000$ ) (Table 2, Figure $4 \mathrm{C}$ ).

The mean, median, and SD values of the relationship between the residual endodontic smear layer volume and the RCS volume at coronal, middle, and apical third of the RCS and the isthmus (\%) are displayed in Table 3 and Figure 5A-C. 
Table 3. Descriptive analysis of the relationship between the residual endodontic smear layer volume and the root canal system volume at coronal, middle, and apical third of the RCS and the isthmus (\%) of the study groups.

\begin{tabular}{cccccc}
\hline & & EV & EA & Positive Control & Negative Control \\
\hline \multirow{5}{*}{ Coronal third } & $n$ & 10 & 10 & 10 & 10 \\
& Mean & 3.72 & 7.63 & 7.94 & 10.31 \\
& Median & 2.41 & 8.50 & 8.30 & 9.22 \\
& SD & 3.35 & 3.38 & 4.17 & 7.90 \\
& Minimum & 0.00 & 2.23 & 0.92 & 2.70 \\
& Maximum & 10.06 & 11.59 & 14.20 & 27.75 \\
\hline \multirow{5}{*}{ Middle third } & $n$ & 10 & 10 & 10 & 10 \\
& Mean & 7.97 & 9.11 & 13.40 & 17.70 \\
& Median & 5.56 & 9.66 & 16.97 & 16.13 \\
& SD & 8.62 & 5.44 & 9.56 & 4.89 \\
& Minimum & 0.31 & 0.00 & 0.54 & 47.54 \\
\hline \multirow{5}{*}{ Apical third } & Maximum & 23.87 & 17.21 & 30.43 & 10 \\
& $n$ & 10 & 10 & 10 & 11.84 \\
& Mean & 7.41 & 5.18 & 8.29 & 6.22 \\
& Median & 6.94 & 5.26 & 5.04 & 12.78 \\
& SD & 5.55 & 3.23 & 7.78 & 0.34 \\
& Minimum & 0.35 & 0.43 & 1.37 & 40.54 \\
\hline
\end{tabular}

A

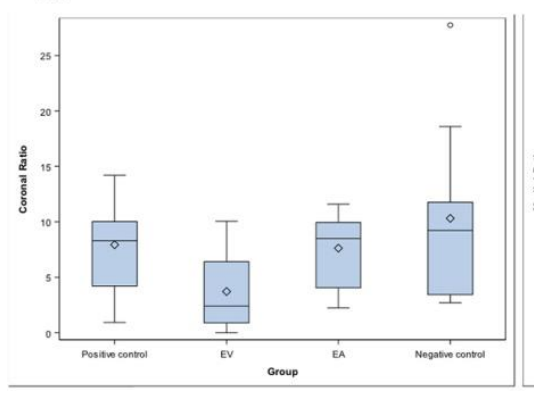

B

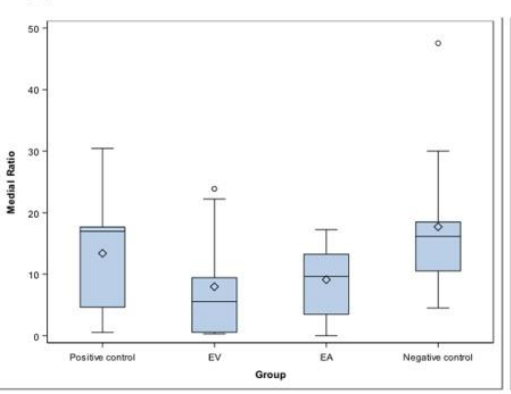

C

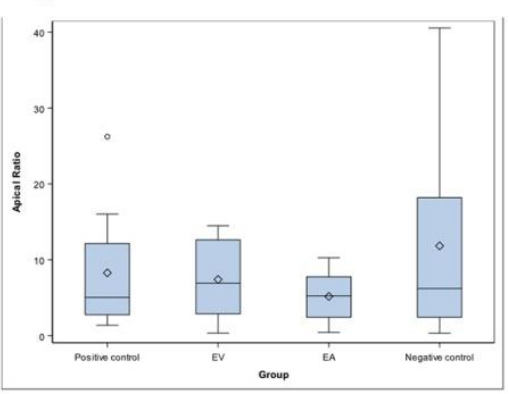

Figure 5. Box plot of the relationship between the residual endodontic smear layer volume and RCS volume in the coronal (A), middle (B), and apical third (C) of the RCS and the isthmus $\left(\mathrm{mm}^{3}\right)$ of the study groups.

The ANOVA test revealed statistically significant differences between the relationship between the residual endodontic smear layer volume and the RCS volume of the root canal systems randomly assigned to the Negative control group at the coronal root third $(10.31 \pm 9.22 \%)$, compared to the EV study group $(3.72 \pm 3.35 \%)(p=0.029)$ (Table 3, Figure 5A). However, there were no statistically significant differences between the study groups regarding the relationship between the residual endodontic smear layer volume and the RCS volume at middle root third ( $p=0.105)$ (Table 3, Figure 5B), or the apical root third ( $p=0.780$ ) (Table 3, Figure 5C).

Briefly, the coronal and middle root thirds of the RCSs randomly assigned to the EA study group showed higher residual endodontic smear layer volume than the EV RCSs randomly assigned to the EA study group; however, the volumes of the RCSs randomly assigned to the EA study group were also higher than the RCSs randomly assigned to the EV study group. By contrast, the apical root third of the RCSs randomly assigned to the EV study group showed higher residual endodontic smear layer volume than the EA RCSs randomly assigned to the EA study group; however, the volume of the RCSs randomly assigned to the EV study group were also higher than the RCSs randomly assigned to the EA study group. Hence, the relationship between the residual endodontic smear layer volume and the RCS volume showed a higher ratio relative to the EA study group at coronal and middle root thirds, 
but a higher ratio related to the EA study group at the middle third. In conclusion, the EV endodontic irrigation system provided higher smear layer removal at coronal and middle root thirds, compared to EA endodontic irrigation system; however, the EA endodontic irrigation system provided higher smear layer removal at the apical root third, compared to EV endodontic irrigation system.

\section{Discussion}

The results presented in this study reject the null hypothesis $\left(\mathrm{H}_{0}\right)$ that determines that there would be no differences between the EndoVac and Endoactivator endodontic irrigation systems for removing the endodontic smear layer present in the coronal, middle, and apical third of the RCS and the isthmus.

This study analyzed the endodontic smear layer removal capacity of two endodontic irrigation systems in the RCS and the isthmus from mesial roots of first lower molar teeth by means of micro-CT analysis [9]. The endodontic smear layer removal has been previously analyzed by Scanning Electron Microscope [11,12] and Confocal Laser Scanning Microscopy [13]; however, these measurement procedures require the longitudinal section of the dental root, only a limited region of the RCS can be analyzed, and does not allow for the measurement of the endodontic smear layer volume [14]. Micro-CT analysis allows an accurate 3D measurement technology to quantify the endodontic smear layer volume in the RCS; however, micro-CT cannot detect the remaining soft tissue and requires tooth extraction as well as the previously described measurement procedures $[15,16]$. Few articles have reported the use of micro-CT technology to analyze the endodontic smear layer removal in the RCS of mesial roots from lower molar teeth and especially containing isthmus [11,17].

It has been reported that the smear layer can contain inorganic dentin debris and organic cells, such as parts of the odontoblastic process, bacterial cells, and necrotic pulp tissue; therefore, it is very important to analyze the ability to remove smear layer from irrigation systems to prevent secondary endodontic infections and facilitate sealing of root canal systems. [18]. It has been reported that $130 \mu \mathrm{m}$ of $\mathrm{NaOCl}$ can be introduced into the dentinal tubules [19], while Enterococcus faecalis can penetrate up to a depth of $151 \mu \mathrm{m}$ and attach to collagen fibers present [20], leaving bacteria harbored in deeper layers, isthmus, accessory canals, anastomoses, and fins [21,22]. Furthermore, endodontic smear layer formation during RCS surgery can cause blockage of dentinal tubules and isthmus, avoiding the effect of $\mathrm{NaOCl}$ inside the RCS [23]. Sjögren et al. reported that negative microbiological cultures obtained from the RCS show a root canal treatment success rate close to $94 \%$. However, positive microbiological cultures reduce endodontic success rate to $68 \%$ [24]. Hence, the elimination of the pathogenic microflora from the RCS is a determinant factor in the outcome of the endodontic therapy. Chelating solutions have created soluble calcium chelates in contact with calcium ions from root dentin to remove the endodontic smear layer, improving the efficacy of $\mathrm{NaOCl}$ inside the RCS [25]. Furthermore, supplemental irrigation procedures after root canal preparation with chelating agents, passive ultrasonic irrigation [13,26], sonic irrigation [27], and apical negative-pressure procedures [13] have been shown to improve the endodontic smear layer removal of the canal walls and also increase endodontic sealer penetration into the dentinal tubules and isthmus. However, few reports have been performed comparing sonic irrigation and apical negative pressure. Overall, in this study the mean endodontic smear layer removal of the EA and EV study groups was reduced from the coronal to the apical root thirds, perhaps because the dentinal tubules reduce its number and diameter toward the apical root third [11] and due to the sclerotic dentin present at the apical root third, which shows a higher resistance to irrigant solutions to remove the smear layer and also to endodontic sealer penetration [9]. This agrees with previous studies, which showed that irrigating solutions are less effective in the apical root third [13]. Although the endodontic irrigation systems showed a statistically significant decrease in the endodontic smear layer volume of the RCS and the isthmus from the mesial root of first lower molar teeth $(p<0.05)$, none of them were able to remove completely the endodontic smear layer present in the coronal, middle, and apical root third of the RCS and the isthmus. These findings are consistent with previous studies $[10,15,28]$, which highlighted the relevance of the endodontic irrigant systems to remove endodontic smear layer formation during RCS preparation, especially in areas of 
anatomical irregularities that cannot be removed with current techniques available [16]. Therefore, this study proposes the development of new endodontic smear layer removal protocols suitable for optimizing and improving the cleaning of the most irregular regions of the RCS and the isthmus from the mesial roots of first lower molar teeth.

The EndoVac endodontic irrigation system comprises an alternative irrigation regimen that involves apical negative pressure and uses a master tip to deliver the irrigant agent into the pulp chamber, while microcannulas are used throughout the entire RCS [29]. Zeliha et al. reported that the EndoVac endodontic irrigation system improved the apical root third disinfection of the RCS because the microcannula allows for the presence of the irrigating solution at the apical region [30]. However, the Endoactivator endodontic irrigation system has been demonstrated to improve coronal and middle root third disinfection of the RCS due to the movement of the Endoactivator tip at coronal and middle root third of the RCS that allows for the penetration of the irrigating solution in the dentinal tubules [20,31,32]. In addition, the EndoVac endodontic irrigation system has reported a mean reduction rate of the smear layer volume in the RCS and isthmus of the mesial roots of first lower molar teeth of $2.12 \%$ [8] and 3.4\% [33].

\section{Conclusions}

Within the limitations of this study, the results show that the endodontic smear layer removal depends on the endodontic irrigation system used and the location in the RCS and the isthmus from mesial roots of first lower molar teeth. The Endoactivator endodontic irrigation system achieves a higher endodontic smear layer removal in the coronal and middle root thirds of the RCS and the isthmus from mesial roots of first lower molar teeth compared to the EndoVac endodontic irrigation system, which allows for a similar endodontic smear layer removal in the coronal, middle, and apical root thirds of the RCS and the isthmus from mesial roots of first lower molar teeth.

Author Contributions: All of the authors contributed to the investigation, supervision, writing, review, and editing of the study. Conceptualization, M.L.-R., V.F.-L., Á.Z.-M., and S.S.; data curation, I.F.-M.; formal analysis, V.F.-M.; visualization, C.R.-S. All authors have read and agreed to the published version of the manuscript.

Funding: This research received no external funding.

Conflicts of Interest: The authors declare no conflict of interest.

\section{References}

1. Arias-Moliz, M.T.; Morago, A.; Ordinola-Zapata, R.; Ferrer-Luque, C.M.; Ruiz-Linares, M.; Baca, P. Effects of Dentin Debris on the Antimicrobial Properties of Sodium Hypochlorite and Etidronic Acid. J. Endod. 2016, 42, 771-775. [CrossRef] [PubMed]

2. de Gregorio, C.; Estevez, R.; Cisneros, R.; Paranjpe, A.; Cohenca, N. Efficacy of different irrigation and activation systems on the penetration of sodium hypochlorite into simulated lateral canals and up to working length: An in vitro study. J. Endod. 2010, 36, 1216-1221. [CrossRef] [PubMed]

3. Adcock, J.M.; Sidow, S.J.; Looney, S.W.; Liu, Y.; McNally, K.; Lindsey, K.; Tay, F.R. Histologic evaluation of canal and isthmus debridement efficacies of two different irrigant delivery techniques in a closed system. J. Endod. 2011, 37, 544-548. [CrossRef]

4. Silva, E.J.N.L.; Carvalho, C.R.; Belladonna, F.G.; Prado, M.C.; Lopes, R.T.; De-Deus, G.; Moreira, E.J.L. Micro-CT evaluation of different final irrigation protocols on the removal of hard-tissue debris from isthmus-containing mesial root of mandibular molars. Clin. Oral Investig. 2019, 23, 681-687. [CrossRef]

5. Tahmasbi, M.; Jalali, P.; Nair, M.K.; Barghan, S.; Nair, U.P. Prevalence of Middle Mesial Canals and Isthmi in the Mesial Root of Mandibular Molars: An In Vivo Cone-beam Computed Tomographic Study. J. Endod. 2017, 43, 1080-1083. [CrossRef]

6. Kim, S.; Jung, H.; Kim, S.; Shin, S.J.; Kim, E. The Influence of an Isthmus on the Outcomes of Surgically Treated Molars: A Retrospective Study. J. Endod. 2016, 42, 1029-1034. [CrossRef]

7. Cleghorn, B.M.; Christie, W.H.; Dong, C.C. Root and root canal morphology of the human permanent maxillary first molar: A literature review. J. Endod. 2006, 32, 813-821. [CrossRef] 
8. Rius, L.; Arias, A.; Aranguren, J.M.; Romero, M.; de Gregorio, C. Analysis of the smear layer generated by different activation systems: An in vitro study. Clin. Oral Investig. 2020, 10, 1-8. [CrossRef]

9. Adorno, C.G.; Fretes, V.R.; Ortiz, C.P.; Mereles, R.; Sosa, V.; Yubero, M.F.; Escobar, P.M.; Heilborn, C. Comparison of two negative pressure systems and syringe irrigation for root canal irrigation: An ex vivo study. Int. Endod. J. 2016, 49, 174-183. [CrossRef]

10. Thomas, A.R.; Velmurugan, N.; Smita, S.; Jothilatha, S. Comparative evaluation of canal isthmus debridement efficacy of modified EndoVac technique with different irrigation systems. J. Endod. 2014, 40, 1676-1680. [CrossRef]

11. Alakshar, A.; Saleh, A.R.M.; Gorduysus, M.O. Debris and Smear Layer Removal from Oval Root Canals Comparing XP-Endo Finisher, EndoActivator, and Manual Irrigation: A SEM Evaluation. Eur. J. Dent. 2020, 10. [CrossRef] [PubMed]

12. Turkyilmaz, A.; Erdemir, A. Comparison of dentin penetration ability of different root canal sealers used with different obturation methods. Microsc. Res. Tech. 2020, 10. [CrossRef] [PubMed]

13. Matos, F.S.; da Silva, F.R.; Paranhos, L.R.; Moura, C.C.G.; Bresciani, E.; Valera, M.C. The effect of 17\% EDTA and QMiX ultrasonic activation on smear layer removal and sealer penetration: Ex vivo study. Sci. Rep. 2020, 10, 10311. [CrossRef]

14. van der Sluis, L.W.; Versluis, M.; Wu, M.K.; Wesselink, P.R. Passive ultrasonic irrigation of the root canal: A review of the literature. Int. Endod. J. 2007, 40, 415-426. [CrossRef] [PubMed]

15. De-Deus, G.; Marins, J.; Neves, A.D.A.; Reis, C.; Fidel, S.; Versiani, M.A.; Alves, H.; Lopes, R.T.; Paciornik, S. Assessing accumulated hard-tissue debris using micro-computed tomography and free software for image processing and analysis. J. Endod. 2014, 40, 271-276. [CrossRef]

16. Paqué, F.; Boessler, C.; Zehnder, M. Accumulated hard tissue debris levels in mesial roots of mandibular molars after sequential irrigation steps. Int. Endod. J. 2011, 44, 148-153. [CrossRef]

17. Estrela, C.; Rabelo, L.E.; de Souza, J.B.; Alencar, A.H.G.; Estrela, C.R.A.; Sousa Neto, M.D.; Pécora, J.S. Frequency of Root Canal Isthmi in Human Permanent Teeth Determined by Cone-beam Computed Tomoghy. J. Endod. 2015, 41, 1535-1539. [CrossRef]

18. Violich, D.R.; Chandler, N.P. The smear layer in endodontics-A review. Int. Endod. J. 2010, 43, 2-15. [CrossRef]

19. Cheng, X.; Guan, S.; Lu, H.; Zhao, C.; Chen, X.; Li, N.; Bai, Q.; Tian, Y.; Yu, Q. Evaluation of the bactericidal effect of Nd:YAG, Er:YAG, Er,Cr:YSGG laser radiation, and antimicrobial photodynamic therapy (aPDT) in experimentally infected root canals. Lasers Surg. Med. 2012, 44, 824-831. [CrossRef]

20. Harrison, A.J.; Chivatxaranukul, P.; Parashos, P.; Messer, H.H. The effect of ultrasonically activated irrigation on reduction of Enterococcus faecalis in experimentally infected root canals. Int. Endod. J. 2010, 43, 968-977. [CrossRef]

21. Cheng, X.; Qu, T.; Ma, C.; Xiang, D.; Yu, Q.; Liu, X. Bioactive mono-dispersed nanospheres with long-term antibacterial effects for endodontic sealing. J. Mater. Chem. B. 2017, 5, 1195-1204. [CrossRef] [PubMed]

22. Dioguardi, M.; Di Gioia, G.; Illuzzi, G.; Arena, C.; Caponio, V.C.A.; Caloro, G.A.; Zhurakivska, K.; Adipietro, I.; Troiano, G.; Lo Muzio, L. Inspection of the Microbiota in Endodontic Lesions. Dent. J. 2019, 7, 47. [CrossRef]

23. Machado, R.; Ferrari, C.H.; Back, E.; Comparin, D.; Tomazinho, L.F.; Vansan, L.P. The Impact of Apical Patency in the Success of Endodontic Treatment of Necrotic Teeth with Apical Periodontitis: A Brief Review. Iran. Endod. J. 2016, 11, 63-66. [PubMed]

24. Sjögren, U.; Figdor, D.; Persson, S.; Sundqvist, G. Influence of infection at the time of root filling on the outcome of endodontic treatment of teeth with apical periodontitis. Int. Endod. J. 1997, 30, 297-306. [CrossRef] [PubMed]

25. Souza, M.A.; Hoffmann, I.P.; Menchik, V.H.S.; Zandoná, J.; Dias, C.T.; Palhano, H.S.; Bertol, C.H.; Rossato-Grando, L.G. Influence of ultrasonic activation using different final irrigants on antimicrobial activity, smear layer removal and bond strength of filling material. Aust. Endod. J. 2019, 45, $209-215$. [CrossRef] [PubMed]

26. Dioguardi, M.; Di Gioia, G.; Illuzzi, G.; Ciavarella, D.; Laneve, E.; Troiano, G.; Lo Muzio, L. Passive Ultrasonic Irrigation Efficacy in the Vapor Lock Removal: Systematic Review and Meta-Analysis. Sci. World J. 2019, 12,6765349 .

27. Johnson, M.; Sidow, S.J.; Looney, S.W.; Lindsey, K.; Niu, L.N.; Tay, F.R. Canal and isthmus debridement efficacy using a sonic irrigation technique in a closed-canal system. J. Endod. 2012, 38, 1265-1268. [CrossRef] 
28. Paqué, F.; Laib, A.; Gautschi, H.; Zehnder, M. Hard-tissue debris accumulation analysis by high-resolution computed tomography scans. J. Endod. 2009, 35, 1044-1047. [CrossRef]

29. Mozo, S.; Llena, C.; Chieffi, N.; Forner, L.; Ferrari, M. Effectiveness of passive ultrasonic irrigation in improving elimination of smear layer and opening dentinal tubules. J. Clin. Exp. Dent. 2014, 6, e47-e52. [CrossRef]

30. Uğur, A.Z.; Erdönmez, D.; Ateş, M.O.; Doğan, T. Efficacy of different irrigation activation systems on bacterial extrusion. Aust. Endod. J. 2020, 10. [CrossRef]

31. Leoni, G.B.; Versiani, M.A.; Silva-Sousa, Y.T.; Bruniera, J.F.; Pécora, J.D.; Sousa-Neto, M.D. Ex vivo evaluation of four final irrigation protocols on the removal of hard-tissue debris from the mesial root canal system of mandibular first molars. Int. Endod. J. 2017, 50, 398-406. [CrossRef] [PubMed]

32. Siqueira, J.F., Jr.; Alves, F.R.; Versiani, M.A.; Rôças, I.N.; Almeida, B.M.; Neves, M.A.; Sousa-Neto, M.D. Correlative bacteriologic and micro-computed tomographic analysis of mandibular molar mesial canals prepared by self-adjusting file, reciproc, and twisted file systems. J. Endod. 2013, 39, 1044-1050. [CrossRef] [PubMed]

33. Freire, L.G.; Iglecias, E.F.; Cunha, R.S.; Dos Santos, M.; Gavini, G. Micro-Computed Tomographic Evaluation of Hard Tissue Debris Removal after Different Irrigation Methods and Its Influence on the Filling of Curved Canals. J. Endod. 2015, 41, 1660-1666. [CrossRef] [PubMed]

(C) 2020 by the authors. Licensee MDPI, Basel, Switzerland. This article is an open access article distributed under the terms and conditions of the Creative Commons Attribution (CC BY) license (http://creativecommons.org/licenses/by/4.0/). 